\title{
Analgesia postoperatoria materna - cirugía fetal cierre mielomeningocele. Experiencia Hospital Carlos Van Buren
}

\author{
Márquez D. ${ }^{1}$, Astele F. ${ }^{1,2}$, López N. ${ }^{1,2}$ \\ 1 Universidad de Valparaíso, Valparaíso, Chile. \\ 2 Hospital Carlos Van Buren, Valparaíso, Chile.
}

Introducción: El Mielomeningocele es una malformación congénita caracterizada por un defecto en el desarrollo y cierre del tubo neural. La cirugía de corrección fetal, ha demostrado ser útil para revertir la herniación cerebral secundaria y ha disminuido la necesidad de derivación de líquido céfalo raquídeo postnatal. A pesar, que se han desarrollado múltiples protocolos de manejo quirúrgico y anestésico orientados a la corrección prenatal del defecto (con énfasis en resultados perinatales), no existen publicaciones sobre el manejo analgésico postoperatorio seguro de estas pacientes. En este estudio se describe el manejo analgésico durante las primeras 24 horas postoperatorias de pacientes, sometidas a cirugía abierta para el cierre de defectos del tubo neural fetal en nuestro centro.

Métodos: Estudio retrospectivo descriptivo de pacientes sometidas a cirugía reparación abierta de mielimeningocele fetal, en Hospital Carlos Van Buren (Valparaíso), Chile, entre diciembre de 2014 - julio de 2019. Se analizaron 18 fichas, incluyéndose 17 pacientes que tenían registro completo, con edades gestacionales entre 23 - 26 semanas, feto único y diagnóstico de mielomeningocele prenatal. La técnica anestésica empleada fue anestesia general (Sevorane, y Remifentanil - TCI) asociada o no a analgesia neuroaxial, paracetamol y/o AINES en postoperatorio.

Resultados: En 15 de 17 pacientes (88\%) se utilizó Morfina intratecal preoperatoria, en rango de 80 - 120 ug. Se obtuvo analgesia satisfactoria en un 73\% (11/15) de éstas, (considerando satisfactorio EVA $<4 / 10$ hasta las $24 \mathrm{~h}$ siguientes). En 4 de 15 pacientes con morfina se asoció el uso de analgesia peridural con bolo intermitente programado (Bupivacaína 0,1\%). En 3 pacientes de éstas últimas se logró analgesia satisfactoria. Las pacientes que no recibieron morfina intratecal fueron manejadas con Metamizol en infusión y Paracetamol oral. Dos pacientes requirieron morfina endovenosa (ev) de rescate. Complicaciones como náuseas y vómitos fueron referidas en el grupo de morfina intratecal en $29 \%$ de los casos y en $100 \%$ del grupo de Morfina ev. No reportamos otras complicaciones del uso de opiodes (prurito, retención orina y depresión respiratoria).

Conclusiones: La morfina intratecal fue la técnica analgésica más utilizada en estas pacientes, logrando analgesia satisfactoria en la mayoría. Complicaciones como náuseas y vómitos postoperatorios estuvieron presentes en un tercio de esta serie. No se reportaron otras complicaciones. Dadas las limitaciones propias del estudio, falta evidencia que nos permita establecer un esquema analgésico estandarizado y seguro para este grupo de pacientes, sin embargo, parece prometedor la utilización de opioides neuroaxiales y/o anestésicos locales en modalidad PCEA.

https://doi.org/10.25237/congresoclasa2019.86 